\title{
Sense of Agency in Times of Automation: A Teachers' Professional Development Proposal on the Ethical Challenges of AI Applied to Education
}

\author{
Ana Mouta ${ }^{1(\bowtie)}$, Eva Torrecilla Sánchez ${ }^{2(\bowtie)}$, \\ and Ana María Pinto Llorente ${ }^{2(\varpi)}$ \\ ${ }^{1}$ Doctoral School, University of Salamanca, Salamanca, Spain \\ id00771513@usal.es \\ ${ }^{2}$ Faculty of Education, University of Salamanca, Salamanca, Spain \\ \{emt,ampintoll\}@usal.es
}

\begin{abstract}
The possibilities given by artificial intelligence are becoming enactments of what once were just distant fictional displays. Even if we restrict the context to Artificial Intelligence in Education (AIEd) the horizon is still wide. But which society layers and ethical frameworks are being considered in the process of conceiving AIEd scope? Committed with this debate, this research focuses the ethical challenges of AIEd in terms of sense of agency development across formal education.
\end{abstract}

Keywords: Artificial intelligence $\cdot$ Education $\cdot$ Ethics $\cdot$ Sense of agency $\cdot$ Training

\section{Introduction: Who's Accountable for Automation Applied to Learning Processes?}

The latest technological advancements emerging as daily commodities are so farreaching that our ways of thinking, feeling, acting and relate with others may be transformed at a very silent and rapid pace. But what investments are being made to determine the kind of culture, usage and ethics people want, need and may be able to spread through their technology mediated performances? In fact, works on ethical assessment of new tech, including AI-powered environments, are gaining traction [1, 2]. Education-wise huge worldwide governmental investments were made for the deployment of laptops, broad access to Internet and educational software, some integrating AI [3], intelligent tutoring systems [4], and robots [5]. Although we may consider relevant some achievements over the last 25 years, AIEd is quite a new discipline and a research overview revealed a lack of critical reflection of its challenges and risks $[6,7]$. In fact, AIEd is covering an unprecedent range of cognitive functions and easing some routine tasks through automated grading, feedback loops, virtual facilitators, personalised learning, customised materials, and proctoring. But ideologies, fantasies, and projections about what the future should or is expected to be inform the 
development of these technological solutions. So, who may be accountable for AIEd development and scope? How is sense of agency being enhanced or constrained in the processes it enables? And how is our Judgement of Agency [8] being respected by its automations? In fact, many studies emphasised the sense of agency role in user experience and interface design [9] and some found a conundrum in the association of automation and sense of agency $[10,11]$. This $\mathrm{PhD}$ research is being developed under the premise that sense of agency is at the heart of learning, enabling experiences of signification that may foster lifelong orientation for learning. It also considers sense of agency core for legal and ethical structures [12]. So, this research aims at contributing to the public debate on AIEd, so that its researchers/developers become more sensitive and critical towards ethical learning-related issues. Furthermore, it intends to foster teachers' critical thinking on AIEd, by directly recognising their current attitudes and levels of awareness on the matter. Teachers are expected to be empowered to decide whether they want to use AIEd or not, to recognise the ways these technologies enter and may transform classrooms and learners and how they may integrate these resources into their pedagogical practices.

\section{Research Goals and Methodology: Designing the Futures We Long for}

\subsection{Research Goals}

This work aims at understanding if and how ethical impact assessment of AIEd influences primary teachers' awareness on the challenges AIEd may pose [13] to sense of agency. The specific goals comprise: (1) the exploration of contexts, applications, drivers, ethical issues, and controls that may be critical to evolve in the discussions of AIEd, particularly in what relates to sense of agency. (2) The enhancement of teachers' capacity to explore AI impact on learning, across students' different developmental tasks. (3) The design of professional development content that promotes teachers' capability to intentionally consider AI ethical challenges in their pedagogical practices, preserving the conditions that enable students' sense of agency.

\subsection{Methodology}

The research methodology will be mainly qualitative, comprising data triangulation. On the first phase it will be used a grounded theory-based design of a framework for teachers' Continuing Professional Development (CPD). This part will include the following variables: the narrative shared participatory methods and the capability of ethically reason upon AI applied to Education. Given the fact that this research's theoretical corpus is on its first growing years, the option for the Delphi method seemed accurate, enabling the identification of guiding theories, variables, causal relationships, constructs, instruments and generating a common language for discussion [14]. The structure is planned as follows: 1.1. Selection of a group of circa 15 experts from different geographical realities (snowball method), with experience on education, philosophy of technology, tech applied to education or in AI software development. 
1.2. Participants will be challenged (email) to express their opinions on AIEd - i.e., AIEd techs and applications, user contexts, usage drivers, ethical issues involved, and existing controls. 1.3. This data will enable the construction of a survey questionnaire. 1.4. Participants will (a) rethink their first responses, (b) choose the 2 main critical items for each criterion, and (3) conclude on the drivers, the potential ethical challenges, and the current existing controls. Data will be analysed through descriptive statistics that will be further shared with the experts. 1.5. These new ideas will be voted by the group to define a final list on each criterion and further create a hypothetical dilemma reflecting an ethical challenge posed by AIEd. 1.6. Participants will vote 3 dilemmas (better exploration of AIEd ethical challenges). 1.7. Results will be shared with the entire group.

Then, providing directions on CPD needs, a focus group of circa 7-10 teachers will be presented 3 ethical dilemmas (resulting from the previous research design). This will constitute a common basis to identify what AI tech might be like and speak about the AIEd construct. Teachers will be invited to choose the most impactful dilemma in terms of learning implications, justifying their choices. They are expected to highlight potential consequences to students' sense of agency resulting from the use of that tech under the described circumstances (or others). Then, teachers will be also invited to explore the needs of a school community in what concerns AIEd. This content will be analysed (CAQDAS) to explore teachers' current attitudes towards AIEd and related CPD needs.

The content resulting from the Delphi and focus group phases will be the basis for designing a socio-constructivist eLearning course. Its methodologies will create opportunities to explore and evaluate teachers' capacity to intentionally integrate the potential and limits of using AI. A group of around 20 teachers or education internship students will be invited to complete this online course (MOOC platform). A qualitative data collection moment on attitudes towards AIEd will be included in the initial and final phases of the course structure. Throughout the course teachers will (1) identify AIEd applications, (2) explore its potential and challenges in terms of learning, and (3) specifically identify the effects of AIEd ethical challenges upon sense of agency. Then, a group of around 5 teachers will be invited to a final semi-structured interview to grasp teachers' attitudes towards AIEd regarding learning experiences' processes. The eLearning characteristics that might have contributed to those results will be explored along with the teachers' perception on their capability and will to continue dealing with the ethical challenges AI may pose to formal educational environments. The questions will also comprise the main criteria teachers consider relevant for CPD on AIEd.

\section{Conclusions}

This research is expected to mainly reinforce understanding on the critical ethical dimensions of AI applied to Education, in what concerns the role of sense of agency in the signification of a learning experience. It will reflect upon the perspective of different educational stakeholders, namely teachers, and it will try to contribute to the public debate and further research on AIEd. That will be done through the development of 
conceptual insights and theoretical frameworks to analyse and incorporate its critical dimensions into deliberate pedagogical practices.

\section{References}

1. Brey, P.: Ethics of emerging technologies. In: Hansson, S.O. (ed.) Methods for the Ethics of Technology. Rowman and Littlefield International (2017)

2. Reisman, D., Schulz, J., Crawford, K., Whittaker, M.: Algorithmic impact assessment: a practical framework for public agency accountability (2018). https://ainowinstitute.org/ aiareport2018.pdf

3. Becker, B.: Artificial intelligence in education: what is it, where is it now, where is it going? In: Ireland's Yearbook of Education 2017-2018, pp. 42-46. Education Matters (2017)

4. Craig, S.: Tutoring and Intelligent Tutoring Systems. Nova Science Publishers, New York (2018)

5. Vitanza, A., Rossetti, P., Mondada, F., Trianni, V.: Robot swarms as an educational tool: the Thymio's way. Int. J. Adv. Robot. Syst. (2019). https://doi.org/10.1177/1729881418825186

6. Humble, N., Mozelius, P.: Artificial Intelligence in Education - a Promise, a Threat or a Hype? (2019). https://doi.org/10.34190/eciair.19.005

7. Zawacki-Richter, O., Marín, V.I., Bond, M., Gouverneur, F.: Systematic review of research on artificial intelligence applications in higher education - where are the educators? Int. J. Educ. Technol. Higher Educ. 16, 39 (2019). https://doi.org/10.1186/s41239-019-0171-0

8. Synofzik, M., Vosgerau, G., Newen, A.: Beyond the comparator model: a multifactorial twostep account of agency. Conscious. Cogn. 17, 219-239 (2008). https://doi.org/10.1016/j. concog.2007.03.010

9. Moore, J.W.: What is the sense of agency and why does it matter? Front. Psychol. 7 (2016). https://doi.org/10.3389/fpsyg.2016.01272

10. Berberian, B., Sarrazin, J.-C., LeBlaye, P., Haggard, P.: Automation technology and sense of control: a window on human agency. PLoS ONE 7, e34075 (2012). https://doi.org/10.1371/ journal.pone. 0034075

11. Sahaï, A., Desantisb, A., Grynszpand, O., Pacheriea, E., Berberian, B.: Action corepresentation and the sense of agency during a joint Simon task: comparing human and machine co-agents. Conscious. Cogn. 67, 44-55 (2019). https://doi.org/10.1016/j.concog. 2018.11.008

12. Frith, C.D.: Action, agency and responsibility. Neuropsychologia 55, 137-142 (2014). https://doi.org/10.1016/j.neuropsychologia.2013.09.007

13. Aiken, R., Epstein, R.: Ethical guidelines for AI in education: starting a conversation. Int. J. Artif. Intell. Educ. 11, 163-176 (2000). https://www.researchgate.net/publication/ 228600407_Ethical_guidelines_for_AI_in_education_Starting_a_conversation

14. Cabero, J., Infante, A.: Empleo del Método Delphi y su empelo en la investigación en comunicación y educación. Revista Electrónica de Tecnología Educativa 48, 1-16 (2014). https://idus.us.es/bitstream/handle/11441/32234/edutec-e_n48_cabero-infante.pdf? sequence $=1 \&$ is Allowed $=\mathrm{y}$ 